\title{
Study on stress and coping strategies among private and government high school children in Udupi Taluk, Karnataka-A cross sectional study
}

\author{
Shubhi Tomar ${ }^{1}$, Garima Verma ${ }^{2}$, Anuj David ${ }^{2}$, Megha Thakur ${ }^{2}$, Miti Judith \\ Ogorchukwu ${ }^{2}$, Purnima Parmar ${ }^{2}$, Prafulla Shriyan ${ }^{2}$, Richa Jaswal ${ }^{2}$ \\ 1(Department of Public Health/Manipal University, India) \\ 2(Department of Public Health/Manipal University, India)
}

\begin{abstract}
Introduction :Stress is experienced by adolescent in everyday life when they percieve situation which cannot be managed by them. Methodology : A cross sectional study has been conducted to measure the stress level and their coping mechanism to deal with such situations in Udupi Taluk.A total of 200 students were included in the study from private and government school. Result : The result shows that students likely to suffer from severe mental disorders are $3 \%$ in private school and $2 \%$ in government school due to their academic burden, relationship with parents and friends. In both the schools majority of sudents talk to their parents, watching television, playing out with friends to cope up with these situations. Conclusion :Stress becomes unmanagable when students are not able to cope with undesirable situations and they beleive that the challenge is impossible to complete.
\end{abstract}

Keywords: adolescent, stress, parents

\section{INTRODUCTION}

Adolescence is a stage where transition occurs from childhood towards the adulthood. Adolescence can be generally defined as the period of life when a child develops into an adult generally seen during 12 19 years. In an education system adolescents are receiving education in junior and senior high schools. During this phase of development they face rapid physical and mental changes due to which they can sometimes feel incompatible with the changes around their physical and social environment. Adding to this are academic factors which causes further problems. [1]

These children face various stressors and which in turn lead to stress when they are not able to cope up with these stressors. Stress can be explained in terms of sadness, worries, tension, frustration which leads to depression which is temporary or may last for long. It has been found in many studies that severely depressed school children are more prone to suicide attempts [2].Some of the common reasons of stress can be problems with the parents, siblings, problems in the school, problems with the studies, teachers, classmates etc. the problem starts with normal stress among the individual with can turn to distress and result in many health problems both biological and psychological [2].

Academic pressure by the parents as well as the children are themselves tensed about their career and future, when fail to cope up with the situation or fail to satisfy their needs then it results into stress and depression. Adolescents are the budding future of a nation and it is imperative for the teachers, parents and caregivers to understand the factors which might be stressful to adolescents and recognize ways to help them cope up with such situation.

\section{Methodology}

From the list of schools in udupi taluk two schools(one government and one private) were randomly selected for the study. Students of class $9^{\text {th }}$ and $10^{\text {th }}$ were taken. Out of three sections in each class one section was randomly selected and all the student who were present that day were taken.

Self administered questionnaire was used to assess the stress levels which consist of questions regarding demographic information [3] like socioeconomic status etc., information regarding educational pressure on children like marks in exams and their satisfaction with the marks[4], information regarding their relationship with their families[5] and friend and how this affects stress level, and question regarding mechanism of coping to these stress levels.

Kessler 10 scale questionnaire was used to determine level of stress among children. The Kessler Psychological Scale (K10) is designed to measure stress, anxiety and depression through a 10-item questionnaire. Each question symbolize emotional state and each has a five-level response scale. The values of the response categories are reversed: 5 - all of the time to 1 - none of the time. These 10 statements are summed 
to give scores ranging from 10 and 50, where 50 indicates high risk of anxiety or depressive disorder. It took 20 minutes to complete the questionnaire by each student. [6]

For statistical analysis, descriptive and logistic regression was done using SPSS version 15.0.

\section{Results}

The study included 200 participants, 100 each from government and private school. In private schools the mean age of participants is $14.59 \pm 0.996$ years $(69 \%$ males and $31 \%$ females) and in government school its $14.72 \pm 0.854$ years (54\% males and $46 \%$ females). $90 \%$ of participants are Hindus in private school while $96 \%$ are Hindus in government school. In both schools maximum number of participants is kannada speaking $(88 \%$ in private and $75 \%$ government).

The analysis of category wise Kessler's score shows that in all the categories government school children tend to have less degree of mental disorders as compare to private school children. (table 1). Regression results indicate that there is significant relationship among stress disorders in children of both the schools and academic factors and factors related to their relationship with family and friends (table 2). Government school children are better acclimatized to use coping strategies as compared to private school children (table 3 )

\section{Discussion}

In a study done in Daily life stress and its correlates among high school students in Hualien city, school work, concern with prospects, parent-teen relationship and peer relationship were found to be the main sources of daily life stress perceived[7], in this study also the academics and relationship with parents and peers is major stressors among participants.

Another study has been done among high school students in a rural region of Tennessee, also reported academic class work, concern about grades, pressures to succeed and achieve, feelings about self-worth and personal respect, peer acceptance, relationships with friends; and "problems" at school as a stressor[8].

According to the study of Academic Stress and Adjustment Among High School Students of Public and Government high school in Delhi. The Results of this study was similar as our study as it indicates that magnitude of academic stress was significantly higher among the private school students where as Government school students were significantly better in terms of their level of adjustment coping strategies[9].

\section{Conclusion}

Stress becomes unmanagable when students are not able to cope with undesirable situations and they beleive that the challenge is impossible to complete. The solution is to adapt to the situation and try to overcome the stress. A bad stress can be changed to good stress when it motivates the students and keep them energized to do best work.

\subsection{LIMITATIONS}

This study lacks representativeness as only two schools were selected one of each type. There can be Information bias present as self reported questionnaire type is used. The temporal relationship between stress and its factors cannot be made because both exposure and outcome are measured at same time.

\subsection{RECOMMENDATIONS}

Promotion of support system from peers, family members in learning communication skills- to enhance peer-relationship and friendship Stress among students can be minimised by making study pattern easy, interactive classroom sessions, less expectations from grades, minimize conflicts with friends, not to compare with other students. Exercise and sports along with extracurricular activities should be encouraged to cope stress and depression. Students should be provided a psychological, social and academic counselling in order to decrease stress. Career guidance should be given to frame their primary spheres of interest, to identify longrange goals and prepare them for decision making

\section{Acknowledgement}

The authors acknowledges the school authority of both the schools, students who participated in the study, Mr Teddy Andrews. 


\section{References}

[1] Cheng Kai-Wen, A study of stress sources among college students in Taiwan, Journal of Academic and Business Ethics.

[2] Walker J, Adolescent Stress and Depression. [online], 2005, [Cited 2014 Jan]; [1]. Available from: http://www.extension.umn.edu/youth/research/adolescent-stress-and-depression/

[3] Taragar S, Stressors among the students of high school, Department of human development college of rural home science, dharwad university of agricultural sciences, Dharwad, June, 2009.

[4] Gupta M, Gupta R, MishraSC and Sharma S, An Examination of the Relationship between Academic Stress and Academic Achievement in Secondary Classes Students of Meerut, VSRD-TNTJ, 2011; 2 (7);320-325.

[5] Deb S, Chatterjee P, Walsh K, Anxiety among high school students in India: Comparisons across gender, school type, social strata and perceptions of quality time with parents, Australian Journal of Educational \& Developmental Psychology, $2010 ; 10 ; 18$ - 31.

[6] The Kessler Psychological Distress Scale (K10). Department of health Population Research and Outcome Studies. brief reports Number : 2002-14.

[7] Li YM, L Y, Daily life stress and its correlates among high school students in Hualien city, Kaohsiung J Med Sci., 1998 Apr;14(4):234-41.

[8] Peach, Larry, A Study Concerning Stress among High School Students in Selected Rural Schools, Annual Education Conference, Tennessee Tech University, August 12, 1991.

[9] Hussain A, Kumar A, Husain A, Academic Stress and Adjustment Among High School Students, Journal of the Indian Academy of Applied Psychology, April 2008; 34(Special Issue); 70-73.

\section{TABLES}

Table 1: Category wise Kessler's score:

\begin{tabular}{|l|l|l|}
\hline Kessler's categories & Private (\%) & Government (\%) \\
\hline likely to be well & 66.0 & 78.0 \\
\hline likely to have a mild mental disorder & 23.0 & 15.0 \\
\hline likely to have moderate mental disorder & 8.0 & 5.0 \\
\hline likely to have a severe mental disorder & 3.0 & 2.0 \\
\hline
\end{tabular}

Table 2: Association of Kessler scoring with various factors: Private school

\begin{tabular}{llll}
\hline & B & P value & Exp (B) \\
\hline Depressed with lower marks & 1.184 & .015 & 4.018 \\
Compare performance with class mates & 1.923 & .003 & 5.148 \\
Less involved in house work & 1.357 & .033 & 3.197 \\
Quarrel with siblings & 3.212 & .022 & 1.998 \\
Restriction in going out & .798 & .032 & 2.894 \\
Not as good as class mates & 2.543 & .001 & 6.985 \\
Underestimated capabilities & .057 & .010 & .066 \\
Death in family & 4.793 & .058 & 8.978 \\
Publically humiliated & 2.128 & .002 & 12.621 \\
\hline
\end{tabular}

Table 3: Association of Kessler scoring with various factors: Government school

\begin{tabular}{llll}
\hline & B & P value & Exp (B) \\
\hline Depressed with lower marks & 1.383 & .018 & 3.985 \\
Compare performance with class mates & 1.839 & .008 & 6.287 \\
Less involved in house work & 1.424 & .028 & 4.154 \\
Quarrel with siblings & 3.301 & .020 & 2.713 \\
Restriction in going out & .869 & .023 & 2.449 \\
Not as good as class mates & 2.009 & .000 & 7.452 \\
Underestimated capabilities & 2.715 & .015 & .092 \\
Death in family & 4.215 & .063 & 8.538 \\
Publically humiliated & 1.993 & .008 & 11.271 \\
\hline
\end{tabular}


Table 3: Coping strategies:

\begin{tabular}{|c|c|c|c|}
\hline Strategies & Categories & Government & Private \\
\hline \multirow{3}{*}{ Practise your religion } & Never & 6 & 3 \\
\hline & Seldom & 73 & 66 \\
\hline & Often & 21 & 31 \\
\hline \multirow[t]{5}{*}{ Free time } & Out with friends & 13 & 8 \\
\hline & Listen to music & 8 & 5 \\
\hline & Reading & 26 & 33 \\
\hline & Watching TV & 29 & 20 \\
\hline & Play sports or games & 24 & 34 \\
\hline \multirow[t]{3}{*}{ When facing problem } & Talk to parents & 46 & 29 \\
\hline & Talk to friends & 53 & 69 \\
\hline & Smoke or drink & 1 & 2 \\
\hline \multirow[t]{2}{*}{ Use smoking for stress } & Yes & 1 & 3 \\
\hline & No & 99 & 97 \\
\hline \multirow{2}{*}{$\begin{array}{l}\text { Family members indulged in } \\
\text { alcohol }\end{array}$} & Yes & 6 & 9 \\
\hline & No & 94 & 91 \\
\hline
\end{tabular}

